\title{
Response Classes in the Dorsal Cochlear Nucleus and Its Output Tract in the Chloralose-Anesthetized Cat
}

\author{
Philip X. Joris \\ Department of Neurophysiology, University of Wisconsin-Madison, Madison, Wisconsin 53706, and Coleman and Epstein \\ Laboratories, Department of Otolaryngology, University of California at San Francisco, San Francisco, California 94143-0526
}

\begin{abstract}
Neurons in the dorsal cochlear nucleus (DCN) can be classified into three major physiological classes on the basis of responses to pure tone and broadband noise stimuli. A circuit diagram that associates these classes with different cell types has been proposed. According to this proposal, type II cells are inhibitory interneurons that respond well to tones and poorly to broadband noise, type IV cells are projection neurons with the opposite behavior, and type III cells are an inhomogeneous class with intermediate properties. To test the associations proposed, I compared the response type distribution in the DCN with its output tract, the dorsal acoustic stria (DAS), in chloraloseanesthetized cats.

Axonal recordings in the DAS showed type III and IV responses as in DCN, but no type II responses. Compared with
\end{abstract}

All auditory information reaching the CNS is channeled through the cochlear nuclear $(\mathrm{CN})$ complex. The dorsal cochlear nucleus (DCN) is the most complex subnucleus, and despite a considerable body of knowledge regarding its physiology and anatomy, its function remains unknown. In an elegant series of studies, Young and his colleagues (Young and Brownell, 1976; Young, 1980; Voigt and Young, 1980, 1988, 1990; Young and Voigt, 1982; Shofner and Young, 1985; Spirou and Young, 1991) constructed a classification scheme of DCN response patterns based on an earlier scheme of Evans and Nelson (1973), and they proposed a correspondence with morphological cell types in a circuit that explains observed response patterns at a qualitative level. Two issues related to this scheme were examined in the current experiments. First, I wished to characterize the DCN input to the midbrain by recording directly from its output tract to differentiate responses of DCN interneurons and projection neurons. The evidence for associations between certain response types and interneurons or projection neurons is incomplete, but few attempts at direct recordings from dorsal acoustic stria (DAS) have been made (Kiang et al., 1973; Adams, 1976), despite the fact that such recordings provide a straightforward means to assess some

\footnotetext{
Received Jan. 15, 1998; revised March 3, 1998; accepted March 4, 1998.

This work was supported by grants from National Institutes of Health (NS-10414), Fulbright, NATO, National Institutes of Health Fogarty International Center, and the Coleman Fund (at the University of California at San Francisco), and by the National Institute on Deafness and Other Communication Disorders Grant DC00116 and National Science Foundation Grant BNS-8901993 (at the University of Wisconsin-Madison). I thank M. M. Merzenich, C. E. Schreiner, P. H. Smith, R. L. Snyder, and T. C. T. Yin for their encouragement and support; C. E. Schreiner and R. L. Snyder for participation in initial experiments; and I. Nelken and P. H. Smith for criticisms on this manuscript. I am grateful for the technical support of R. Kochhar (software) and G. Meulemans (photography).

Correspondence should be addressed to Philip X. Joris, Division of Neurophysiology, K. U. Leuven, Campus Gasthuisberg, B-3000 Leuven, Belgium.

Copyright (C) 1998 Society for Neuroscience $0270-6474 / 98 / 183955-12 \$ 05.00 / 0$
}

reports in decerebrate animals, fewer type IV neurons were encountered having sustained inhibition that generated strongly nonmonotonic responses to tones in both DCN and DAS. The presence of type II responses in the nucleus, but not in the output tract, offers strong support for the proposed association with DCN interneurons. On the other hand, the distinction between type III and IV responses needs refinement because the differences are only graded and because both types of responses occur in DAS, which shows that they are both associated with projection neurons.

Key words: audition; dorsal cochlear nucleus; dorsal acoustic stria; chloralose; response type; cat of the proposed associations. A second issue concerns anesthesia. Progress in understanding of the DCN has been hampered by its susceptibility to anesthesia, which has been demonstrated indirectly by comparison of population statistics for anesthetized and unanesthetized preparations (Evans and Nelson, 1973; Mast, 1973; Kaltenbach and Saunders, 1987; Rhode and Kettner, 1987; Gdowski and Voigt, 1997) and directly for a few individual cells before and after administration of a barbiturate (Young and Brownell, 1976). Many investigators have resorted to a decerebrate preparation, which has other drawbacks. Previous reports (Evans and Nelson, 1973; Young and Brownell, 1976; Kaltenbach and Saunders, 1987; Evans and Zhao, 1993) suggested that anesthesia with $\alpha$-chloralose seemed to affect the inhibition in DCN responses least, but limited data are available in these early studies to assess the generality of this claim.

In this report I compare responses from projection neurons, recorded in the DAS, with responses from DCN (note that the term "projection neuron" does not preclude that these cells functionally have an "interneuronal" role by virtue of collaterals within the cochlear nucleus). To enable comparison with the decerebrate preparation, I used the classification scheme constructed by Young and coworkers (Young and Brownell, 1976; Young, 1980; Voigt and Young, 1980, 1988, 1990; Young and Voigt, 1982; Shofner and Young, 1985; Spirou and Young, 1991), which is based on response maps obtained by graphing average response rates over a range of stimulus frequencies and intensities, as well as on the response to broadband noise. Comparisons will be made largely with published data for the cat, because there are indications for species differences in the proportions of response types (Davis et al., 1996; Stabler et al., 1996; Gdowski and Voigt, 1997). The conclusions drawn therefore may need modification as applied to other species. 


\section{MATERIALS AND METHODS}

Animal preparation. Young adult cats were induced with an intramuscular injection of a mixture of ketamine $(20 \mathrm{mg} / \mathrm{kg})$ and acepromazine $(0.4$ $\mathrm{ml})$. In some animals mucous secretions were reduced with a subcutaneous injection of atropine sulfate or atropine methyl nitrate $(0.1 \mathrm{mg} / \mathrm{kg})$. A cannula was placed in the cephalic vein with a slow drip of Ringer's solution; $60 \mathrm{mg}$ of $\alpha$-chloralose was dissolved in a warm 1:3 mixture of propylene glycol and saline. While the heart rate was monitored, this solution was slowly injected intravenously until no limb withdrawal reflexes could be provoked, and the procedure was repeated when these reflexes returned. In about half the animals, chloralose was supplemented with a slow intravenous injection of diazepam to obtain more complete flaccidity of the limbs. Body temperature was maintained at $37^{\circ} \mathrm{C}$ by a feedback-controlled heating pad. After a tracheotomy was performed, the nuccal ridge and external ear canal(s) were exposed. The ear canal was cut, and the pinna and temporalis muscle were retracted or removed. A craniotomy was performed as laterally as possible without intruding on the squamous portion of the temporal bone. Parts of the lateral cerebellum were aspirated until the DCN was visualized. The electrodes were positioned on the DCN under visual control.

Exposure of the DAS followed the same general approach, but the craniotomy was centered over the midline to allow exposure of both sides. Cerebellum was aspirated, starting at the midline, until the lateral recess and most dorsal portion of the DCN were visualized on left and right side. Fascicles from the DCN can be seen as they cross the inferior cerebellar peduncle and then run medial to descend along the surface of the fourth ventricle (Adams, 1976). The electrode was aimed just medial to the most dorsal point of this crossing. The absence of strong field potentials makes single-unit isolation easier in the DAS than in the fusiform cell layer of the DCN, but a drawback is the difficulty in obtaining stable recordings. After the electrode was positioned, warm $2 \%$ agarose was poured in the posterior fossa to stabilize the brain.

Data collection and analysis. Search stimuli were low-level tones, at the best frequency of the background activity, alternating with broadband noise. Single units were recorded with glass-insulated tungsten electrodes of $~ 3-4 \mathrm{M} \Omega$ (MicroProbe, Clarksburg, MD) or sometimes glass micropipettes ( $3 \mathrm{M} \mathrm{KCl}, \sim 10 \mathrm{M} \Omega$ ), mounted in a hydraulic microdrive controlled from outside the sound-shielded room (IAC). The amplified and filtered neural signal was fed to an audio amplifier, oscilloscope, and window discriminator, which converted action potentials to standard pulses timed by the computer.

Two different setups were used for stimulus generation and data acquisition. Both were custom-made 16-bit digital stimulus systems described previously [Schreiner and Sutter (19920 for the University of California at San Francisco system; Rhode (1976) and Olson et al. (1985) for the University of Wisconsin-Madison, system]. In the first 13 (University of California at San Francisco) experiments, stimuli were delivered monaurally with an electrostatic driver (STAX 54) connected to a plastic earbar via a shielded, metal container modeled after Sokolich (1977). In later (University of Wisconsin-Madison) experiments, monaural and binaural stimuli were delivered with dynamic phones (Chan et al., 1993). In some of these experiments the frequency response of the phones was compensated by a digital filter ("prewhitened") to flatten the spectrum at the output of the sound system (see Results).

All driven and well isolated units were studied. After isolation of a single unit, the approximate characteristic frequency $[(\mathrm{CF})$ the frequency with the lowest excitatory threshold], response to broadband noise, and presence of inhibitory sidebands (if spontaneous activity was present) were noted. Response maps, rate-level functions, and poststimulus time histograms (PSTHs) were then collected and displayed on line. Spontaneous rate (SR), CF, and a general overview of the response of the cell to a range of frequency-sound pressure level (SPL) combinations were obtained from a response map or tuning curve. The response map program presented tone bursts in pseudorandom order of frequency and intensity. Most often, a grid of 45 frequencies over three octaves and in $4 \mathrm{~dB}$ steps was used; tone duration was usually $200 \mathrm{msec}$. In some of the later experiments, a coarser grid of combinations was often used, and each combination was presented multiple times and in nonrandom order. The tuning curve program tracked the excitatory threshold (as described in Geisler and Sinex, 1982) and was used mainly in the DAS recordings to speed data collection.

Rate-level functions were obtained for long duration tone bursts at CF and for broadband noise bursts, with the following parameters: duration 100 or $200 \mathrm{msec}$ with a 1:5 duty cycle, rise-fall times of $10 \mathrm{msec}$, usually 40 repetitions in 5 or $10 \mathrm{~dB}$ increments. If time permitted, a rate-level function to short tone bursts at CF (25 msec every $100 \mathrm{msec}$, rise-fall times of $1.6 \mathrm{msec}$, at least 200 repetitions) was obtained. Spikes were counted over the stimulus duration. To facilitate graphing on a single abscissa, stimulus levels in figures are specified in dB SPL (re $20 \mu \mathrm{Pa}$ ) for tones and with an arbitrary reference (attenuator setting) for broadband stimuli. Noise levels re $20 \mu \mathrm{Pa}$, computed by integrating the stimulus energy over a one-third octave band centered on $\mathrm{CF}$, were close to the attenuator $\mathrm{dB}$ values stated in the figure labels and are specified separately in the figure legends only for those cases in which the difference exceeded $10 \mathrm{~dB}$.

Response classification. Physiological studies of DCN circuit properties have for the most part used a classification scheme in the frequencyintensity domain (the response map scheme), whereas structure-function studies have relied mainly on the time domain (the PSTH scheme) (for review, see Young, 1984; Rhode, 1990). In the classification used by Young and colleagues, three major response categories are distinguished. Quantitative criteria are stated in Results; here a general description is given. Type IV units show high SR, which is inhibited by pure tones over a broad range of frequencies and SPLs. There is typically a small excitatory area of frequency-SPL combinations around the CF, so that rate-level functions obtained at $\mathrm{CF}$ are nonmonotonic. Despite the predominance of inhibitory responses to pure tones, broadband noise stimuli are excitatory at all stimulus levels (Young and Brownell, 1976). Type II units, on the other hand, have low SR, respond weakly or not at all to broadband noise, and have an excitatory response to pure tones (Young and Voigt, 1982). Type III responses show spontaneous activity, an excitatory response to CF tones and broadband noise at all SPLs, and response maps with inhibitory sidebands. They are the least distinctive response type and are found throughout the CN (Shofner and Young, 1985). "Type III+IV" refers to the type III and IV classes combined, not to a new response type.

\section{RESULTS}

Before comparing DAS and DCN responses I shall examine how classification of responses in DCN of the chloralose-anesthetized animal compares with that in the decerebrate preparation. To enable comparison with the diverse classifications used in previous studies, responses are here sorted first on the basis of SR and response to $\mathrm{CF}$ tones, then by the shape of the rate-level functions to broadband noise and CF tones, and finally by the shape of the PSTH pattern over a range of SPLs at CF.

\section{Responses in DCN}

\section{Classification by responses to $C F$ tones and spontaneous rate}

DCN responses encountered under chloralose anesthesia resembled those reported in decerebrate animals. Representative examples of response maps are shown in Figure 1 as iso-level contours (top row) and in a three-dimensional (3-D) format (bottom row) for three cells with similar CF. The response map of the type II cell in Figure $1 A$ is characterized by an absence of spontaneous activity and by orderly rate changes with SPL and frequency. Above the threshold near $40 \mathrm{~dB}$, the firing rate increases steeply with SPL to a maximum rate of 180 spikes/sec and then decreases somewhat to $\sim 150$ spikes/sec at $80 \mathrm{~dB}$. The type III response (Fig. $1 B$ ) has a similar excitatory central portion in the response map showing a monotonic rate increase with SPL, but the cell displays spontaneous activity (arrow on ordinate of top panels) revealing inhibitory sidebands flanking the central area, most strongly on the high-frequency side. The type IV response (Fig. $1 C$ ) is typified by a complex response map with wide areas of frequency-SPL combinations over which spontaneous activity is inhibited. The response to $\mathrm{CF}$ tones has a threshold near $0 \mathrm{~dB}$ SPL and is very nonmonotonic: there is a net increase in the average firing rate over only a restricted range of low SPLs. The central inhibitory area is flanked by excitatory regions.

Table 1 shows the distribution of response types based on SR and rate-level functions to pure tones, to permit comparison with 


\section{A TYPE II}
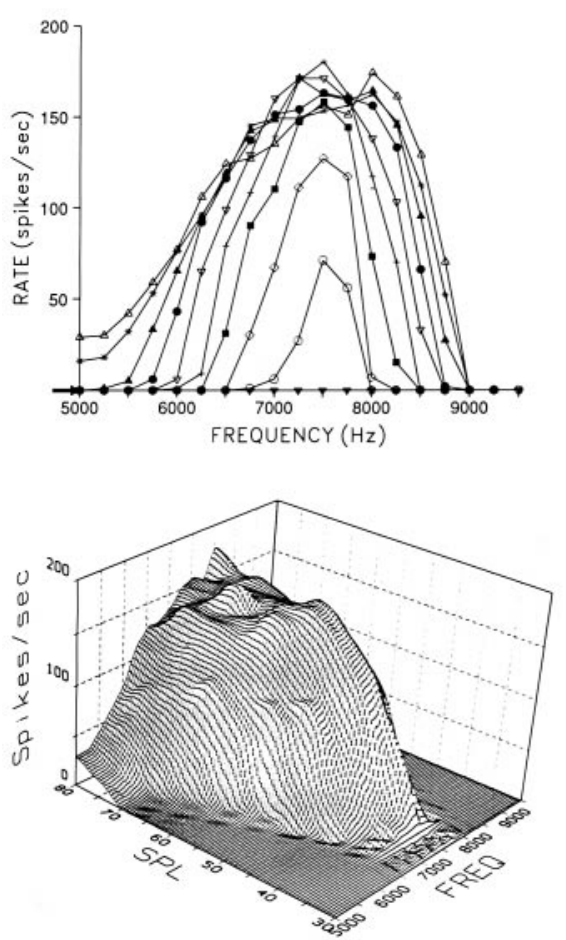

B TYPE III
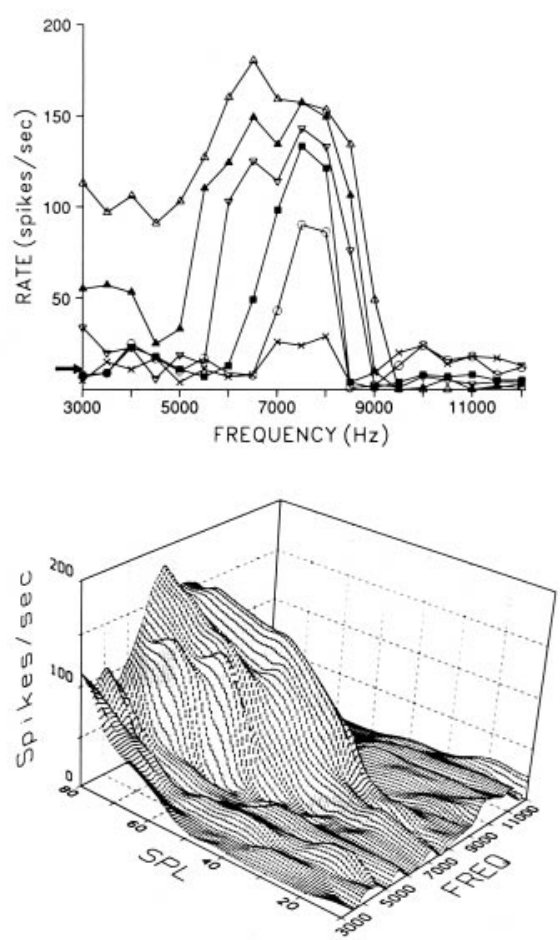

SPL (dB)
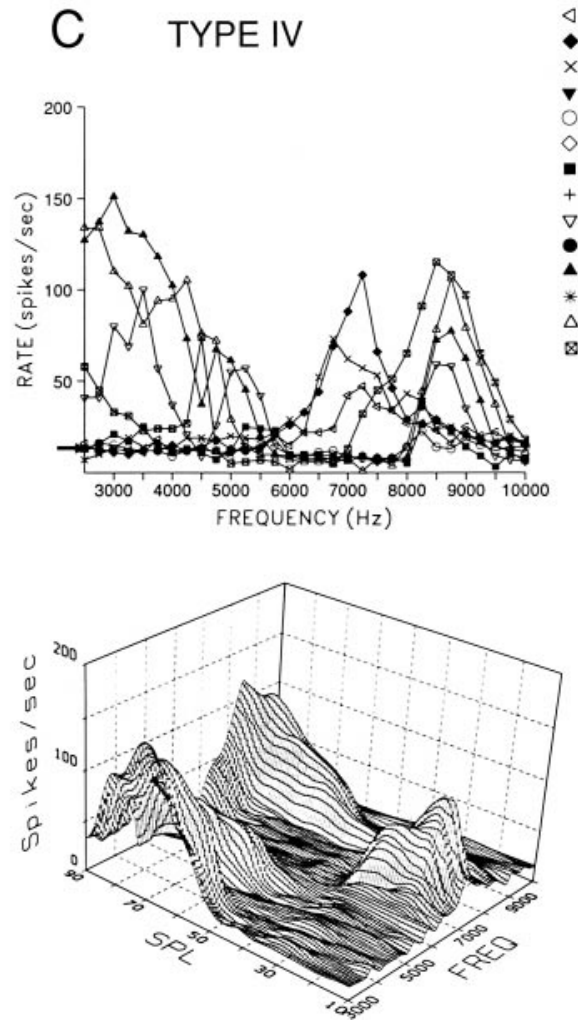

Figure 1. Examples of the three main DCN response types. Data are plotted as response maps (top panels) and in a 3-D format (bottom panels). The type III and type IV units were obtained in the same animal. Horizontal arrows on ordinate of top panels show spontaneous rate (SR). Symbols (inset on right) for different sound pressure levels (SPLs) apply to all top panels. Stimulus parameters (number of presentations $\times$ stimulus duration/repetition interval): $10 \times 100 / 500 \mathrm{msec}$. The characteristic frequency (CF) was $7.5 \mathrm{kHz}$ for $A$ and $B$ and $7 \mathrm{kHz}$ for $C$.

studies in which the response to noise was either not determined (Evans and Nelson, 1973; Rhode and Smith, 1986b; Rhode and Kettner, 1987) or was not the primary criterion used for cell classification (Young et al., 1976, 1982). Cells were assigned to one of three categories, defined by two criteria: nonmonotonicity and SR. If the response was nonmonotonic at $\mathrm{CF}$, the cell was classified as type IV; otherwise it was classified as type II/III. The criterion was that of Shofner and Young (1985). If the driven rate (measured rate - SR) at $35 \mathrm{~dB}$ above rate threshold was less than half the peak rate at lower SPLs, the response was nonmonotonic. With this criterion, nonmonotonic cells include those that are profoundly inhibited by CF tones as well as the so-called type IV N-T cells (Shofner and Young, 1985), in which average rate is not suppressed much below SR. Type II/III cells were subdivided further according to an SR criterion: type II cells have $\mathrm{SR}<2.5$ spikes/sec, and type III cells have $\mathrm{SR} \geq 2.5$ spikes/sec. This criterion was first used by Young and Brownell (1976) and later was shown by Young and Voigt (1982) to segregate cells along other response properties as well.

For the responses recorded in the DCN under chloralose anesthesia ( $n=166$; obtained from 23 animals), types III $(n=71$; $43 \%)$ and IV $(n=68 ; 41 \%)$ neurons were represented equally, with type II cells constituting the remaining $16 \%$ of the sample $(n=27)$. The mean SR (Table 1, numbers in parentheses) of type III cells lay between that of types II and IV. Early in this experimental series, one animal was studied under barbiturate anesthesia; here type III responses dominated, with type IV cells constituting only $10 \%$ of the sample, and average SR was lower.
Comparison with previous studies is difficult for various reasons (see Discussion). Nevertheless, there is sufficient consistency to discern the following trends (Table 1). In decerebrate animals, $\sim 50 \%$ of the cells sampled are type IV, $25 \%$ are type II, and $25 \%$ are type III. It appears that under chloralose, responses in the type III category increased at the expense of type IV cells, a shift that is even more dramatic under barbiturate anesthesia. The increase in type II responses under barbiturate, relative to chloralose, is possibly explained by a general decrease in SR. Similar effects of barbiturate anesthesia on response type distribution and average SR, relative to the awake (Rhode and Kettner, 1987) or decerebrate state, are present in the data of Rhode and Smith (1986b) (Table 1). The distribution obtained under chloralose anesthesia thus is intermediate between those seen in decerebrate preparations and those from barbiturate-anesthetized animals.

\section{Classification by responses to tones and broadband noise}

Young and Voigt (1982) pointed out that monotonic (types II and III) cells that differ in SR also differ in their responses to broadband noise: cells with low SR respond poorly to noise, whereas those with high SR show generally higher response rates. Accordingly, type II and III classes were redefined on the basis of a relative noise ratio $\rho$ (Young and Voigt, 1982; Shofner and Young, 1985; Davis et al., 1996), which is defined as [maximum driven rate to broadband noise]/[maximum driven rate to a $\mathrm{CF}$ tone]. Monotonic units with a poor response to noise, resulting in $\rho<0.3$, were classified as type II; if $\rho$ was $>0.3$ they were classified as type III. For units with a nonmonotonic response to 


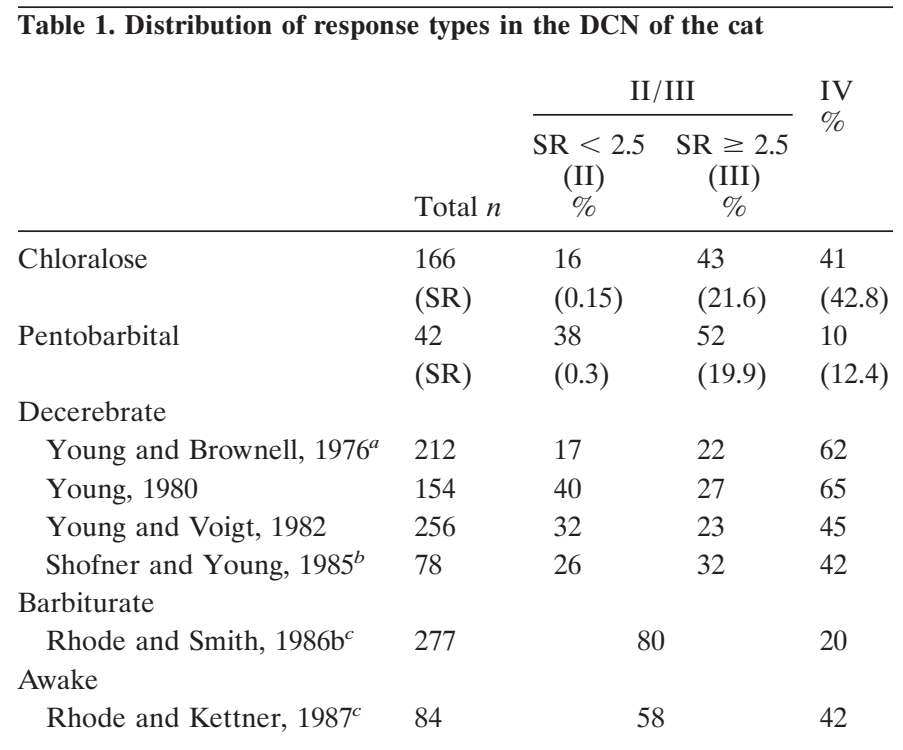

Distribution, in percent, of response types, and comparison with other studies. Classification for data of present study (top rows) was based on the response map (rate-level function at CF), or on the rate-curve to long tones, when available. The Pentobarbital data are from a single animal. Total $n$ (left column) refers to number of cells used in the calculation of percentages; numbers in parentheses give average SR (in spikes per sec). Some of the values of published reports, provided for comparison, are recalculated percentages because response type distribution was often not a primary aim in these studies and is not always stated as such.

${ }^{a}$ One animal out of 28 was studied under chloralose anesthesia.

${ }^{b}$ Recalculated percentages for types II, III, and IV. Distinction between types II and III was made not only on the basis of SR, but also on the basis of response to noise. Out of a total of 108 cells, 30 did not fit into either of these categories: most (24 of 108 ) of these were classified as type I/III because of a lack of SR. Percentages calculated according to the criteria used in the older studies would presumably be 42 for type II, 24 for type III, and 35 for type IV.

${ }^{c}$ Percentages are monotonic (type II/III) and nonmonotonic (type IV) responses as quoted in Table 1 of Rhode and Kettner (1987). Responses to broadband noise were not reported in these studies.

tones, the maximum rate used to calculate $\rho$ was taken at the first local maximum above threshold.

Examples of rate-level functions to $\mathrm{CF}$ tones and broadband noise for the three responses types are shown in Figure 2. The rate-level curve to $100 \mathrm{msec} \mathrm{CF}$ tones (Fig. $2 \mathrm{~A}, \times$ ) of the type II cell rises steeply to a maximum, then declines. There is no response to broadband noise (Fig. $2 A, \square$ ). The relationship between the responses to $\mathrm{CF}$ tones and broadband noise is reversed in the type IV unit (Fig. 2C), where there is a high response rate to noise but little response to tones, except at low SPLs. Finally, CF tones and broadband noise cause similar maximal firing rates in the type III cell (Fig. $2 B$ ). The $\rho$ values for the cells in Figure 2 were near 0 for the type II cell and near 1 for the type III and type IV cell.

Qualitatively, the shape of the tonal rate-level functions usually was affected minimally by the stimulus parameters, although these parameters could affect the response quantitatively. In 19 cells, rate-level functions were obtained to both short and long tone durations over a wide range of SPLs. Five cells with a monotonic response to $100 \mathrm{msec}$ tones had a nonmonotonic response to $25 \mathrm{msec}$ tones. There were no cells with a change in the opposite direction. The remaining cells were consistently monotonic $(n=6)$ or nonmonotonic $(n=8)$ for either stimulus regimen.

Particularly for type III and IV cells, the strength of the tonal response and the degree of nonmonotonicity often depended on
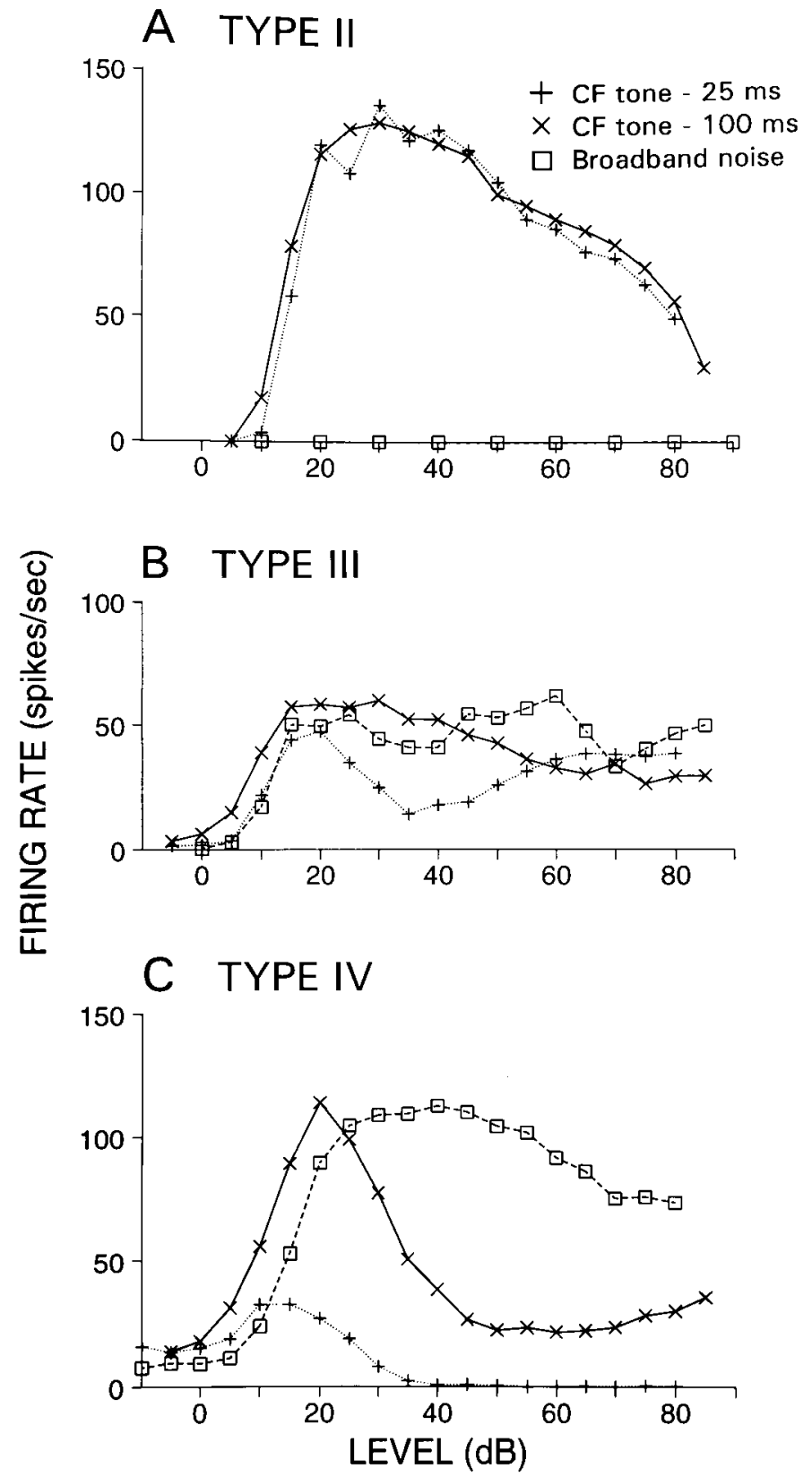

Figure 2. Representative rate-level functions for types II, III, IV. Relative noise ratios ( $\rho$, defined in Results) were 0.002, 1.03, and 0.99, respectively. Stimulus parameters: $40 \times 100 / 500 \mathrm{msec}$ for noise $(\square), 50 \times$ $100 / 500 \mathrm{msec}$ for long tone bursts $(\times), 200 \times 25 / 100 \mathrm{msec}$ for short tone bursts $(+)$. Tone bursts were at the CF (in kilohertz) of each cell; $A$, 9.5; $B, 15.3 ; C, 11.6$

the stimulus duration and repetition parameters. The cell in Figure $2 B$ was monotonic to $100 \mathrm{msec}$ tone bursts but nonmonotonic to short $(25 \mathrm{msec}$ ) tone bursts (for another example, see Fig. $4 D)$. The cell in Figure $2 C$ was nonmonotonic with both stimulus durations, but with short duration tones $\rho$ was much larger (3.5 for $25 \mathrm{msec}$ tones, 0.99 with $100 \mathrm{msec}$ tones), and the response to tones was suppressed below SR. For type II cells, the shape of the rate-level functions and the relative response strengths to tones and noise did not depend on stimulus duration; short and long tone burst rate-level functions superimposed (Fig. $2 \mathrm{~A}$ ), or more commonly, the latter were simply scaled down with respect to the former, having no effect on unit classification (see Fig. 4B). 
NONMONOTONICITY

TO CF TONES

Response @ $35 \mathrm{~dB}$ re. Thr.

$<$

$1 / 2$ peak driven rate?

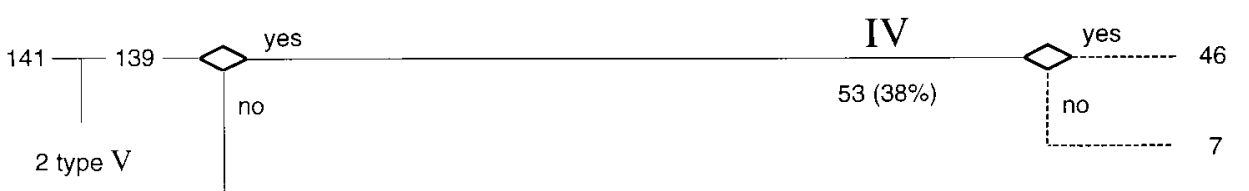

RESPONSE TO

BROADBAND NOISE

$\frac{\text { peak driven rate to NOISE }}{\text { peak driven rate to CF TONE }}>0.3$ ?

86

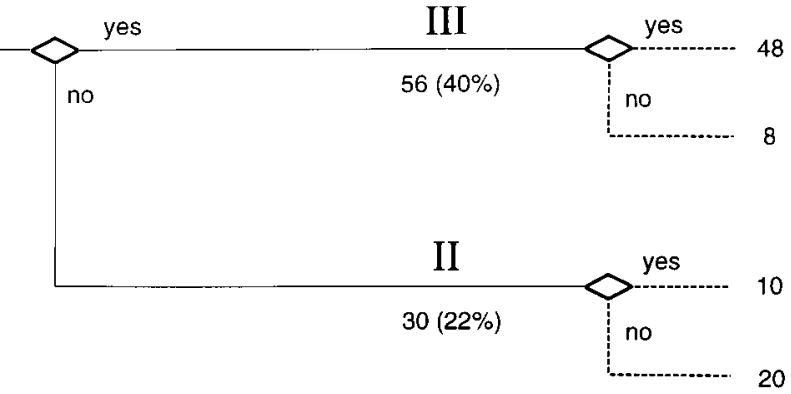

Figure 3. Decision tree for classification of cells on the basis of response to tones and broadband noise. The two main branch points correspond to the two main criteria used: nonmonotonicity and relative response to noise. Number and percentage of cells in each branch are indicated. Dashed lines and criterion on the right indicate inhomogeneities in the resulting classes revealed by $S R$.
Figure 3 shows the categorization of 141 units for which quantitative data for both noise and CF tones were available, a subset of the 166 units of Table 1 . To reduce subjectivity the categorization is performed with binary decisions based on the two quantitative criteria used previously by Young and coworkers (Young and Brownell, 1976; Young, 1980; Voigt and Young, 1980, 1988, 1990; Young and Voigt, 1982; Shofner and Young, 1985; Spirou and Young, 1991). Note, however, that these authors defined response classes on the basis of a cluster of properties, which included these criteria but did not follow a strict hierarchical classification tree.

Of the 141 cells, two showed exclusively inhibitory responses to either tones or noise (type V) and are not considered further. The nonmonotonicity criterion separated type IV from type II and III cells, and the latter two types were distinguished on the basis of $\rho$. The response to long tone bursts was used to assess nonmonotonicity, except for a minority of cells $(\sim 20 \%)$ for which only the short $(25 \mathrm{msec})$ tone burst response was available. Parcellation of 139 units into these three response categories yielded $30(22 \%)$ type II cells, $56(40 \%)$ type III cells, and $53(38 \%)$ type IV cells. In a recent sample of similar size in the decerebrate cat and using the same classification criteria (although not a binary decision tree), Nelken and Young (1994) obtained 18\% type II cells, $33 \%$ type III cells, and 52\% type IV cells. Thus, as was the case with the distribution obtained with the SR criterion (Table 1 ), the present data show a preponderance of type III over type IV responses in comparison with decerebrate animals. The proportion of type II responses to the total is similar in both preparations.

In terms of signal processing abilities, differences in response to narrow versus broadband stimuli are presumably more important than SR, and $\rho$ is therefore intrinsically a more satisfactory criterion with which to separate types II and III than is a distinction that relies merely on the basis of SR (Table 1). Nevertheless, the subpopulations resulting from strict application of the quantitative classification criteria (Fig. 3) are inhomogeneous and unsatisfactory in several respects. First, a number of type II cells appeared to be miscategorized as type IV because of a strongly nonmonotonic rate-level function. Application of the SR criterion (Fig. 3, dashed lines) to the type IV category reveals seven cells with $\mathrm{SR}<2.5$ spikes/sec (of which six had $\mathrm{SR}=0$ spikes/sec). Two examples are shown in Figure $4 A, B$; it is clear that these cells fit into the type II category (compare Fig. $2 A$ ) better than into the type IV category, both because of their poor response to noise and because of the shape of the rate-level function to tones. Many type II cells in the decerebrate animal are also nonmonotonic (Young and Voigt, 1982), but the nonmonotonicity is a sloping decrease in rate with respect to SPL rather than the sharp drop in firing rate at low SPLs seen in type IV cells (compare Fig. $2 A, C)$. Moreover, the response of type II cells is typically incompletely suppressed at high SPLs. Although it is not entirely clear whether the seven cells with low SR are type II cells with a marked degree of nonmonotonicity or type IV cells with low SR and a poor response to noise, these seven cells will be classified as type II in the remainder of the analysis.

Conversely, 10 cells classified as type II cells stood out from the rest of that population (Fig. 3) by virtue of their high SRs $(>2.5$ spikes/sec; mean $=26.4$ spikes $/ \mathrm{sec}$ ). Two examples are shown in Figure $4 C, D$. The high SR and other considerations suggest that these cells should be classified with type III or IV cells. They showed PSTH patterns most commonly associated with type $\mathrm{III}+\mathrm{IV}$ cells (six Pauser-Buildup, one ON-OFF, one Negative responder, one Unusual; see below for explanation of PSTH patterns). Moreover, cells with poor noise responses were also 
Figure 4. Examples of responses inconsistent with general properties of their class. $A, B$, Two cells that were classified as type IV based on their nonmonotonic response to long (100 msec) CF tones $(\times)$, but that are more consistent with type II because of the absence of SR and the nearly absent response to noise ( indicates that noise stimulus was prewhitened). $C, D$, Two cells classified as type II based on their monotonic response to long duration tones and low relative noise response $\rho$ (RNR). Note nonmonotonicity of response in $D$ to short (25 msec, +) CF tones. CFs (kilohertz) were $A$, $4.75 ; B, 38.3 ; C, 13 ; D, 33$. Stimulus parameters are as in Figure 2. For $B$, an attenuator setting of $100 \mathrm{~dB}$ corresponds to a noise level of $81 \mathrm{~dB}$.

recorded in DAS (see below), and there are other indications in the literature (Young and Brownell, 1976; Kim et al., 1990; Nelken and Young, 1994; Davis et al., 1996) and in the present sample that some type III+IV cells have a low response to broadband noise. To distinguish cells with high SR and poor response to noise from cells with low SR and no response to noise, $\rho$ can simply be redefined as the ratio of absolute rather than driven rates, i.e., without subtracting the SR. This ratio is indeed $>0.3$ for 8 of the 10 "problematic" type II cells with high SR.

In addition to the 10 miscategorized type II cells just mentioned, there were an equal number of type III + IV cells for which SR was high $($ mean $=44$ spikes $/ \mathrm{sec})$ and the response to noise inhibitory at one or more SPLs (seven type IV cells, three type III cells). There is thus a sizeable proportion of high-SR cells (20 of 104) that responded poorly to noise but in other respects fit the traditional description of type III or IV categories.

If SR and the modified $\rho$ are used to regroup the cells of Figure 3 , the resulting numbers and percentages are $29(21 \%)$ type II, 64 (46\%) type III, and 46 (33\%) type IV. The composition of these groups is more homogeneous and presumably closer to that in the studies of Young and colleagues (Young and Brownell, 1976; Young, 1980; Voigt and Young, 1980, 1988, 1990; Young and Voigt, 1982; Shofner and Young, 1985; Spirou and Young, 1991; Nelken and Young, 1994), and in the remainder of this paper cells will be analyzed according to this last assignment. In conclusion, responses recorded in this study were similar enough to those in the decerebrate animal to be sorted into the three basic response classes established for that preparation. Nevertheless, there are also some differences, most notably the less frequent appearance of strong and sustained inhibition typical of type IV responses in the decerebrate cat.

\section{RNR}

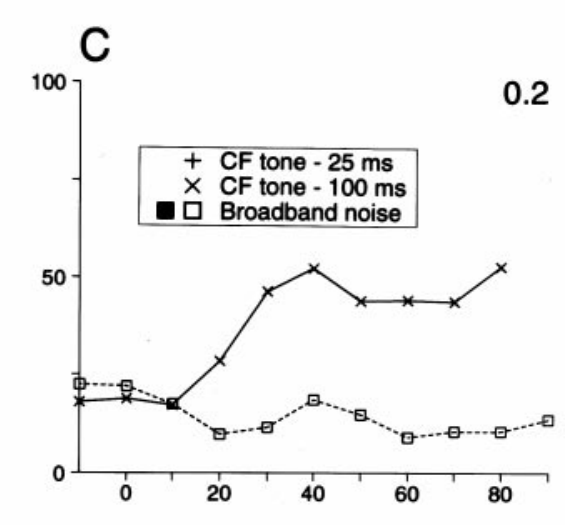

0.2

0.18

LEVEL (dB)

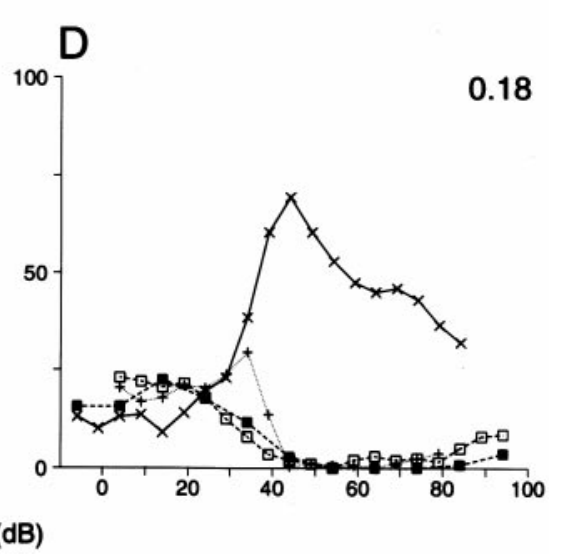

\section{Classification by PSTH}

The time dimension, lost in the calculation of average firing rates, is important to consider. A first indication hereof are the sometimes pronounced differences in firing rate for tones of different stimulus durations and repetition rates (Figs. 2C, 4D). Second, the temporal response pattern, obtained as the PSTH to short tone bursts at $\mathrm{CF}$, provides an alternative classifier that has been used extensively in the $\mathrm{CN}$, particularly in intracellular labeling studies. The correspondence between the two classification schemes has been studied in the decerebrate cat by Shofner and Young (1985). To enable a comparison, we will use the main PSTH categories used in that study.

PTSHs were obtained for 23 type II cells, usually over a wide range $(>50 \mathrm{~dB})$ of SPLs. As in the decerebrate animal (Shofner and Young, 1985), PSTHs of type II cells proved to be diverse and could be assigned to the four categories (Fig. 5): Onset-slow $\left(\mathrm{O}_{\mathrm{s}}, n=9\right)$, Pauser-Buildup $(n=4)$, Chopper $(n=4)$, and Unusual $(n=4)$. Clearly, these assignments are approximate, because responses often displayed features of several of these qualitative categories, sometimes to different degrees at different SPLs. For example, the PSTH in Fig. $5 B$ was categorized as $\mathrm{O}_{\mathrm{s}}$ because response probability tended to be higher around stimulus onset, particularly at lower SPLs, but there clearly is a chopping component in the response.

Type III and IV cells showed various PSTH patterns similar to data published for other preparations (Godfrey et al., 1975b; Shofner and Young, 1985; Rhode and Smith, 1986b; Rhode and Kettner, 1987). The same caveats apply as for the type II cells: PSTH patterns vary with SPL and can show various components at a single SPL. It is shown below (see Fig. 7) that it is particularly the change in PSTH with SPL that sets type III and IV responses 

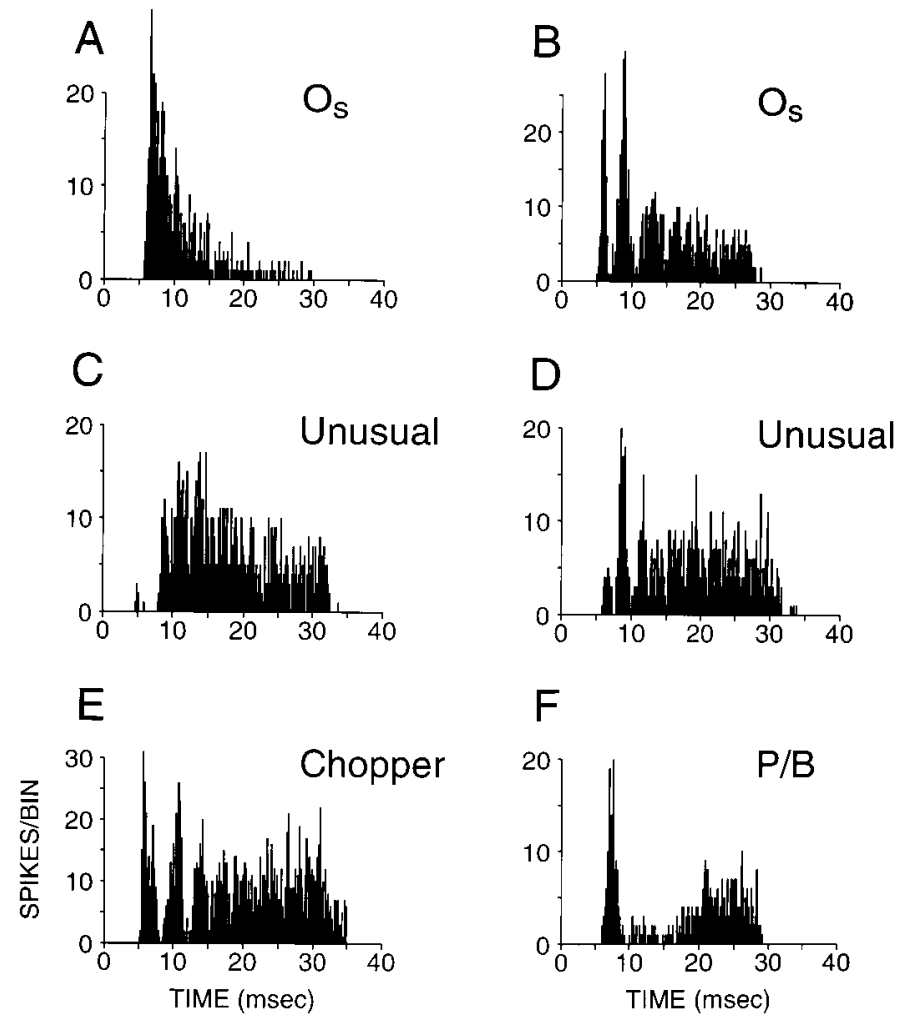

Figure 5. PSTHs of type II cells to $25 \mathrm{msec}$ tone bursts at CF (100 msec interstimulus interval). CFs and SPLs were $(A) 38.3 \mathrm{kHz}, 65 \mathrm{~dB},(B) 4.5$ $\mathrm{kHz}, 75 \mathrm{~dB},(C) 9.5 \mathrm{kHz}, 80 \mathrm{~dB},(D) 9.5 \mathrm{kHz}, 45 \mathrm{~dB},(E) 8.6 \mathrm{kHz}, 80 \mathrm{~dB}$, and $(F) 8.5 \mathrm{kHz}, 75 \mathrm{~dB}$. The number of repetitions was $300(B, F)$ or 200 $(A, C-E)$; number of bins $=200$.

apart from other responses. Here, the PSTH category of a cell is defined by the pattern that reveals the most inhibition and that dominates the response over several SPLs; e.g., if a PauserBuildup pattern is present at low SPLs and an ON-OFF pattern at higher SPLs, the cell is classified as ON-OFF. PSTHs obtained in 33 type III cells were predominantly Pauser-Buildup $(n=15)$ and Chopper $(n=14)$, with only three ON-OFF or $\mathrm{ON}-\mathrm{I}$, one Unusual, and one Negative responder (for examples see below). This distribution is similar to that in the decerebrate cat, in which Shofner and Young (1985) also found a nearly equal number of Pauser-Buildup and Chopper patterns. Type IV cells $(n=21)$ were predominantly Pauser-Buildup $(n=12)$ or ONOFF or ON-I $(n=6)$, with one Chopper, one Unusual, and one Negative responder. In contrast, Type IV responses in the decerebrate animal are characterized by low or no sustained rate, and give almost exclusively transient responses (ON-OFF or $\mathrm{ON}-\mathrm{I})$. This difference is the time-domain equivalent of the difference in rate-level functions pointed out earlier: there is less sound-driven tonic inhibition under chloralose anesthesia than in the decerebrate animal, consequently less nonmonotonicity in responses to tones, and therefore a shift from type IV to type III responses.

\section{Responses in the DAS}

The response variety in the DAS partially overlapped with that encountered in DCN. Comparison of the two sets of data are complicated by the spatial contiguity of the DAS to the intermediate acoustic stria (IAS), which contains axons from the posteroventral CN (PVCN), and by the presence of descending fibers (Fernandez and Karapas, 1967; Warr, 1969; Adams, 1976; Adams and Warr, 1976; Smith and Rhode, 1989). The following analysis is therefore guided by results from intra-axonal labeling experiments, performed in parallel, and using the same exposure and recording strategy (Joris et al., 1992; Joris and Smith, 1995) (P. Smith and P. Joris, unpublished observations). These experiments confirm and extend observations in earlier physiological and anatomical work (Godfrey et al., 1975a,b; Rhode et al., 1983a,b; Smith and Rhode, 1989). Of relevance here, first, is a clear association between certain onset PSTH patterns and cell types: exquisitely timed pure onset responses $\left(\mathrm{O}_{\mathrm{i}}\right)$ are derived from octopus cells in the PVCN, and onset-chopper $\left(\mathrm{O}_{c}\right)$ responses are derived from large multipolar cells in the ventral $\mathrm{CN}$ and deep DCN. Second, these experiments show that the latter multipolar cells can have an extensive axonal arborization within the ipsilateral DCN and give centrally projecting axons that run contiguous to fusiform cell axons in the DAS. These cells thus should be considered in DCN circuitry schemes and are included in the following analysis. Indeed, these cells have recently gained attention as the possible source of wideband inhibition to type IV cells (Nelken and Young, 1994; Winter and Palmer, 1995).

From a total sample of 122 units (obtained from eight animals, two of which also supplied DCN data), the following were excluded: cells with an $\mathrm{O}_{\mathrm{i}}$ response, cells excited by the contralateral ear, and cells for which the recording time was too brief to obtain the response to broadband noise. From the 55 remaining DAS units, three were not considered further because their only response to noise and tones consisted of inhibition or because their response to tones was very low and sluggish.

$\mathrm{O}_{\mathrm{c}}$ responses are characterized not only by the chopping onset pattern in their PSTHs but also by a wide dynamic range of responses to short CF tone bursts (Rhode and Smith, 1986a). Of the 55 units, 10 showed these characteristics, as illustrated by the three examples in Figure 6. The tonal rate-level functions in particular are distinctively expansive, rather than compressive, with increasing SPL. A wide dynamic range is often also present in the responses to noise; however, these functions level off at high SPLs in about half of the cells, perhaps because of the very high discharge rates attained. Although PSTHs (Fig. 6, right panels) may resemble those of type III and IV cells, especially when considered at only a few SPLs, the absence of any nonmonotonicity in the rate-level function and associated pauses in the PSTH make the distinction between $\mathrm{O}_{\mathrm{c}}$ and type III+IV cells clear-cut.

$\mathrm{O}_{c}$ responses have been observed mainly in PVCN recordings [On-type L units in Godfrey et al. (1975a); Rhode and Smith (1986a); Smith and Rhode (1989); Winter and Palmer (1995)], but they also occur in deep DCN near the PVCN border (Godfrey et al., 1975b; Joris et al., 1992). Reexamination of the DCN sample revealed only four cells, categorized as type III (Fig. 3), with expansive rate-level functions. The PSTH to short tone bursts was available only for one of these cells and showed the $\mathrm{O}_{c}$ pattern.

Using the nonmonotonicity and noise response criteria defined earlier ( $\rho$ calculated with absolute rather than driven firing rates), I classified the remaining 42 units as 3 type II, 21 type III, and 18 type IV. The data for the three units shown in Figure 7 were obtained in the same animal. The responses in Figure $7 A, B$ were classified as type IV (nonmonotonicity criterion was barely reached by responses in $B$ ), and those in of Figure $7 C$ were classified as type III. The graded differences between the tonal rate curves in the three panels are representative of the range of behaviors seen across units and illustrate the arbitrariness of the 

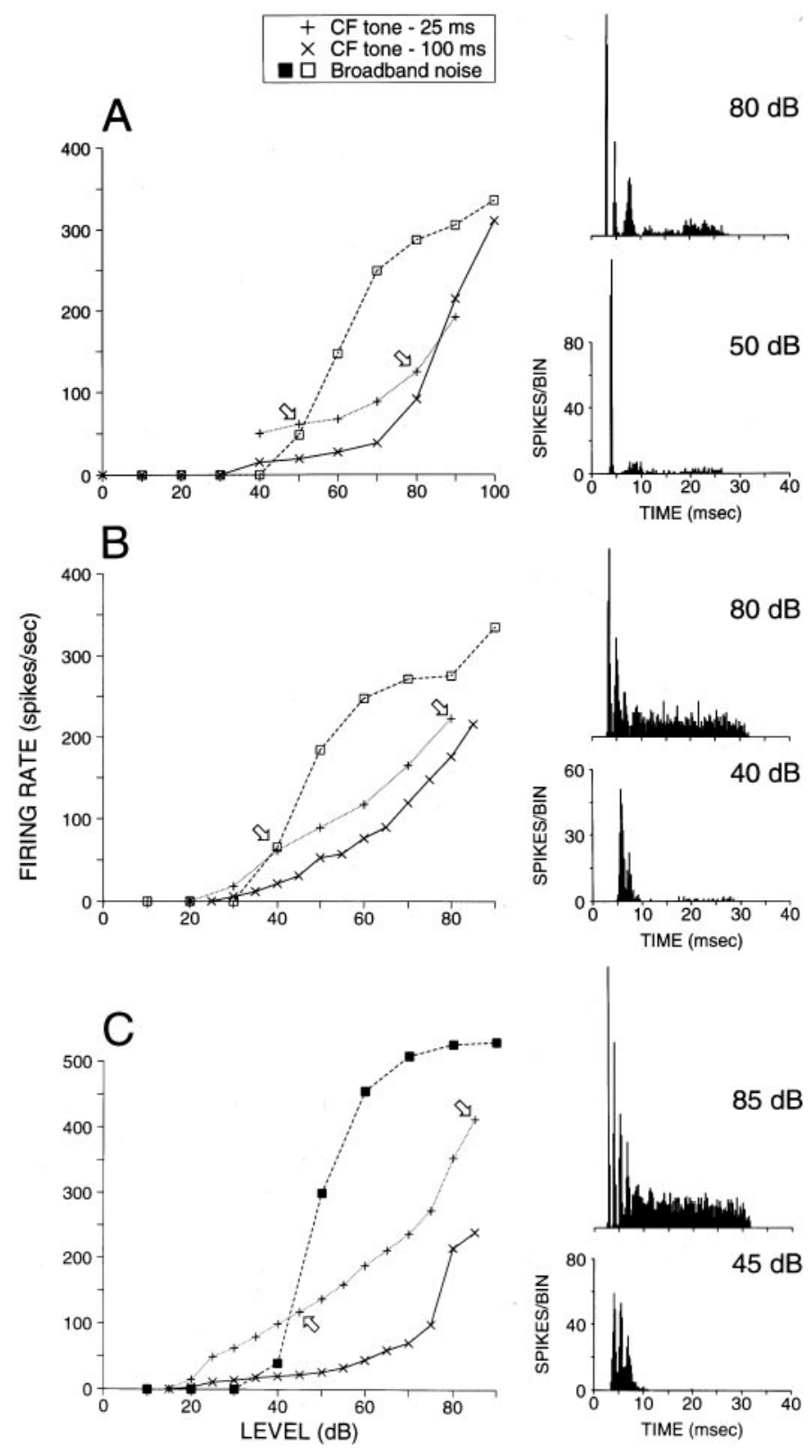

Figure 6. Examples of rate-level functions to tones and noise for three $\mathrm{O}_{\mathrm{c}}$ units recorded in the DAS. PSTHs for $25 \mathrm{msec}$ tone bursts are shown in the right column at two SPLs (arrows). The PSTHs in each panel have the same ordinate scale and number of bins $(200)$. CFs were $(A) 4.8 \mathrm{kHz}$, (B) $23.8 \mathrm{kHz}$, and $(C) 16 \mathrm{kHz}$.

nonmonotonicity criterion. The extent of the inhibitory trough on the SPL axis (Fig. $7 A-C$, left panels) corresponds in the time domain (Fig. 7, right panels) to the degree to which the inhibition is sustained throughout the stimulus duration. Although the PSTHs show various shapes, the progression of PSTH shapes is similar across type III and IV units: sustained (Primary-like or with slow chopping) at low SPLs, with a pause of variable duration at mid-SPLs (giving Pauser-Buildup, ON-OFF, or ON-I pattern), and usually sustained again at the highest SPLs (Pauser or Chopper). Responses having a sustained and profound inhibition over most of the SPL range (Fig. $7 A$ ) predominate in type IV units reported for the decerebrate cat (e.g., Shofner and Young, 1985) but were encountered infrequently here.
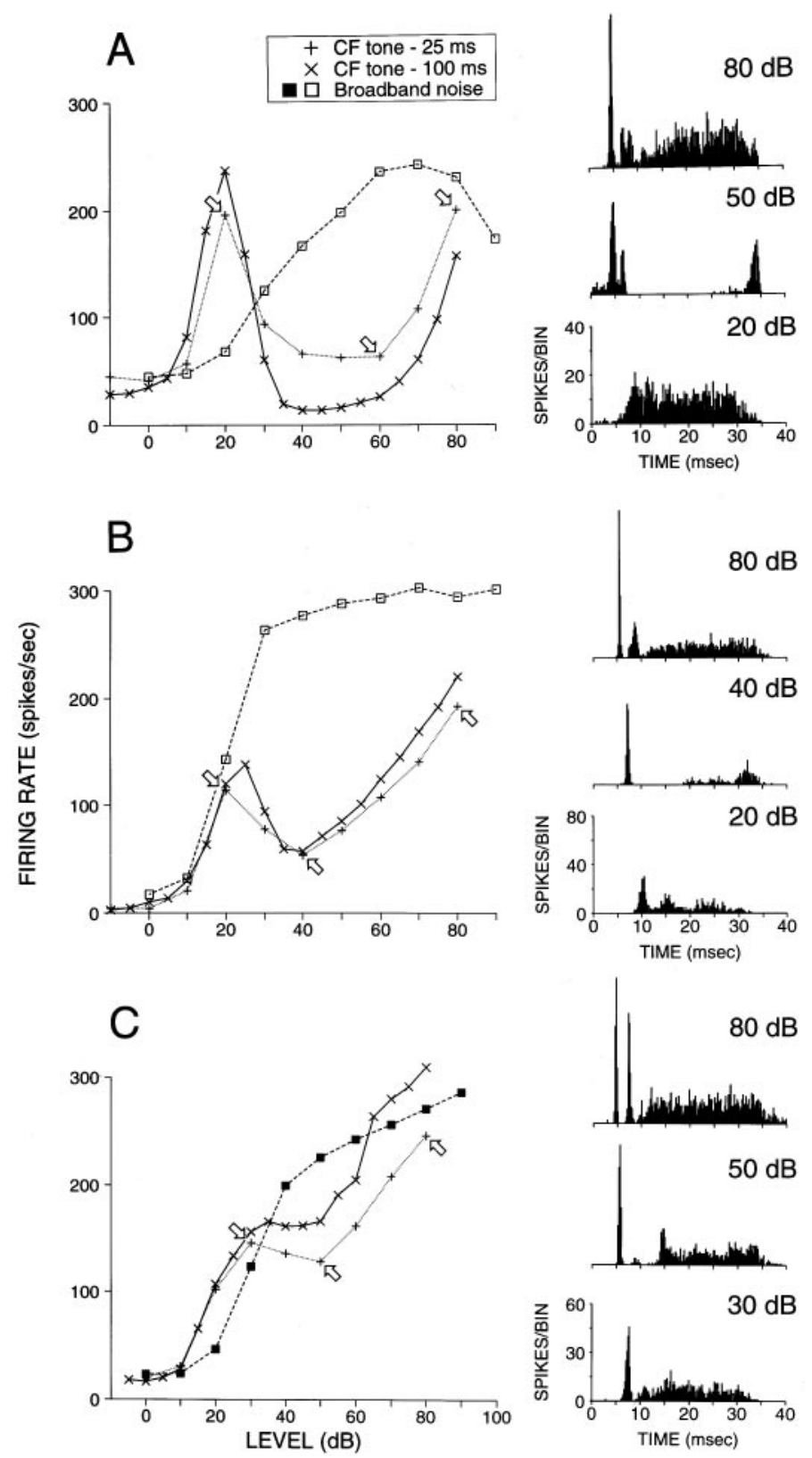

Figure 7. Rate-level functions to tones and noise of three units, recorded in the DAS of one animal, which illustrate similarities between type III $(C)$ and type IV $(A, B)$ responses. Format as in Figure 6. PSTHs in the right column are for the firing rate maxima obtained at a low SPL and at the highest SPL, and for the trough in between (arrows). CFs were $(A)$ $22.8 \mathrm{kHz},(B) 14.7 \mathrm{kHz}$, and $(C) 4.3 \mathrm{kHz}$.

The nearly equal number of type III $(n=21)$ and IV $(n=18)$ responses recorded in the DAS matches well the distribution in the DCN recordings (Fig. 3), consistent with the proposal that type III and IV responses are derived from projection cells of the DCN (Young, 1980). The finding of three type II cells in the DAS, however, seems inconsistent with the presumed association of these responses with DCN interneurons. Rate-level functions and PSTHs of these three units are shown in Figure 8. Only one of these units had $\mathrm{SR}<2.5 \mathrm{spikes} / \mathrm{sec}$, and all showed a rate curve with the inflection at mid-SPLs characteristically found in type III and type IV cells. Comparison with the functions of Figures 2 and 7 shows that these three units are more plausibly classified 

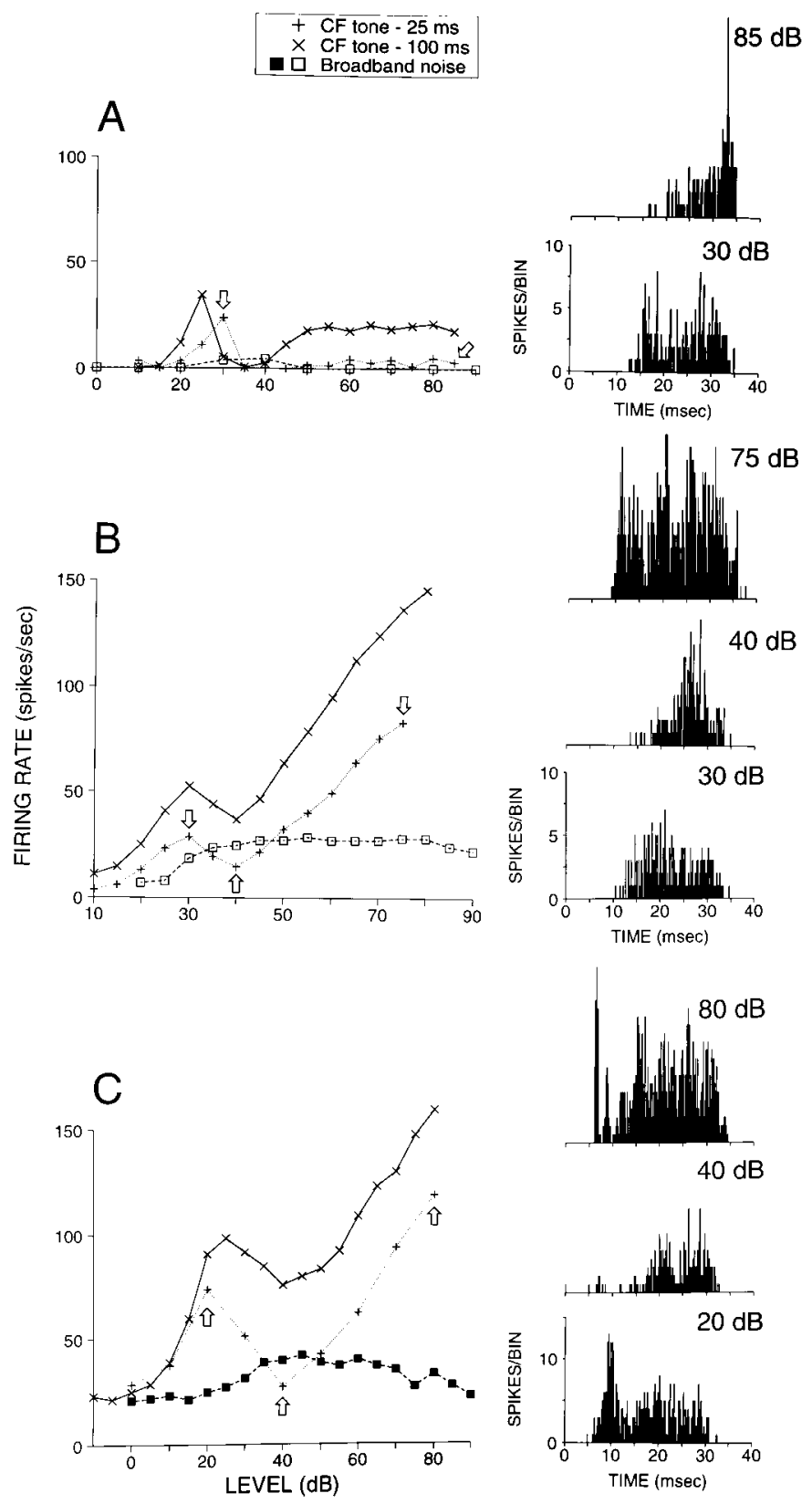

Figure 8. Rate-level functions to tones and noise of three unusual units recorded in the DAS (see Results). Format as in Figure 6. CFs were $(A)$ $1.1 \mathrm{kHz},(B) 1.45 \mathrm{kHz}$, and $(C) 9.6 \mathrm{kHz}$.

as type III cells or as type IV cells that had a poor response to noise rather than as type II cells (as was the case for responses of Figure $4 C, D)$. Note that short and long tone bursts yielded generally similar rate-level function shapes despite sometimes large differences in absolute firing rate (Figs. 6-8; also see Fig. 10).

The scatter plots in Figure 9 provide a summary of the relative responses to $\mathrm{CF}$ tones and noise of all DCN and DAS units. For each unit the maximal firing rate in response to either short (25 $\mathrm{msec})$ or long $(100 \mathrm{msec})$ tone bursts is plotted against the maximal firing rate for broadband noise of the same unit. If rates for both short and long tone bursts were available, both are plotted and joined by a dotted line. Several population trends can be seen. First, $\mathrm{O}_{\mathrm{c}}$ units (Fig. $9 A$ ) stand out by virtue of their large maximal firing rates. Moreover, most $\mathrm{O}_{\mathrm{c}}$ data points are above the diagonal of equality (Fig. $9 A$, dashed line), indicating a higher response to noise. This is in contrast to type II cells, which are all below the solid line indicating the $\rho$ criterion (0.3) used to define this response type. In fact, the opposite behavior of type $\mathrm{II}$ and $\mathrm{O}_{\mathrm{c}}$ units is more dramatic than is illustrated by this figure. Over most of the dynamic range of $\mathrm{O}_{c}$ units, the asymmetry between firing rates to tones and noise is even stronger than implied by the maximum firing rates shown here. This is so because rate-level functions of $\mathrm{O}_{c}$ units to tones are expansive, whereas those in response to noise can be compressive (Fig. 6). Second, as a population, for both tones and broadband noise, maximum rates of type III cells in DAS and DCN are indistinguishable (Fig. 9B), and the same holds true for type IV cells (Fig. 9C) (MannWhitney $U$ test). Third, there is a wide range of maximal response rates in both type III cells (Fig. 9B) and type IV cells (Fig. 9C). The noise response ranges overlap with $\mathrm{O}_{\mathrm{c}}$ responses at the high end and with type II responses at the low end. Interestingly, data points for type IV responses are preponderantly above the diagonal of equality (63\% of 73 data points), whereas type III cells predominate under the diagonal ( $68 \%$ of 127 data points). This is attributable to a larger response to broadband noise in type IV than in type III cells (Mann-Whitney $U ; p<0.001$ ), whereas the maximal response to tones is similar in the two populations (Mann-Whitney $U$; NS). Thus, cells that are more strongly inhibited by tones, and therefore classified as type IV, tend to be more strongly excited by broadband noise than cells with little inhibition to tones, classified as type III. Indeed, there is a weak correlation (data not shown; $r=0.49 ; 64$ measurements in 41 cells) between the driven response to noise and the degree of inhibition to tones, measured as the decrease in firing rate between initial maximum and the minimum at an intensity above this maximum in the rate-level function (e.g., difference in rate at two leftmost arrows in Fig. 7). This is surprising because it is not a simple consequence of the criteria that define these two types (Fig. 3): there is no a priori reason to expect different levels of noise response in type III and IV cells. In fact, the use of the noise criterion to distinguish type II and III (with type III cells having the stronger response to noise), combined with the strong nonmonotonicity and presumably stronger inhibition to tones in type IV cells, points to the opposite prediction.

Review of the results presented so far suggests that the majority of DCN/DAS responses in the cat can be assigned satisfactorily to one of three classes according to a parsimonious scheme that is an amalgam of the two most frequently used classification systems. The three groups are type II, $\mathrm{O}_{\mathrm{c}}$, and $\mathrm{III}+\mathrm{IV}$, and are based on the shape of the PSTH and rate-level functions to short $\mathrm{CF}$ tones (expansive for $\mathrm{O}_{\mathrm{c}}$, nonmonotonic with single maximum for type II, variable for III+IV but usually with two maxima) and the response to noise (small or nonexistent for type II, very high for $\mathrm{O}_{\mathrm{c}}$, variable in type III+IV). In the cases examined, the rate-level function to short ( $25 \mathrm{msec}$ ) and long (100 or $200 \mathrm{msec}$ ) $\mathrm{CF}$ tones generally were similar in shape, but large differences in firing rate occurred (Figs. $2 C, 4 D, 8 C$ ). Presumably because of the lack of sustained inhibition, the short tone rate-level functions usually better revealed nonmonotonic behavior, and they have the added benefit of providing PSTHs at many SPLs (rather than a single PSTH at a fixed suprathreshold SPL).

\section{Responses to notched noise}

The pure tone and noise responses described so far show that some cells in DCN of the chloralose-anesthetized cat have type IV responses similar to those in the decerebrate animal but that 


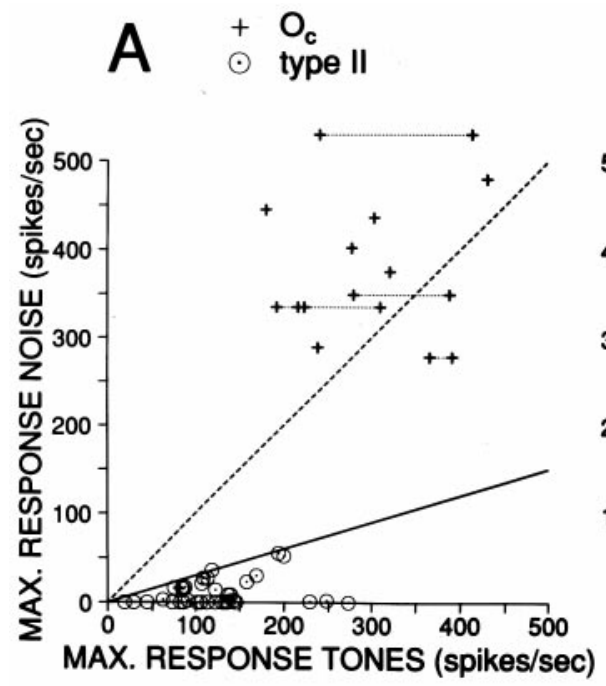

B $\quad \begin{array}{ll}\Delta & \text { type III DCN } \\ \Delta & \text { type III DAS }\end{array}$

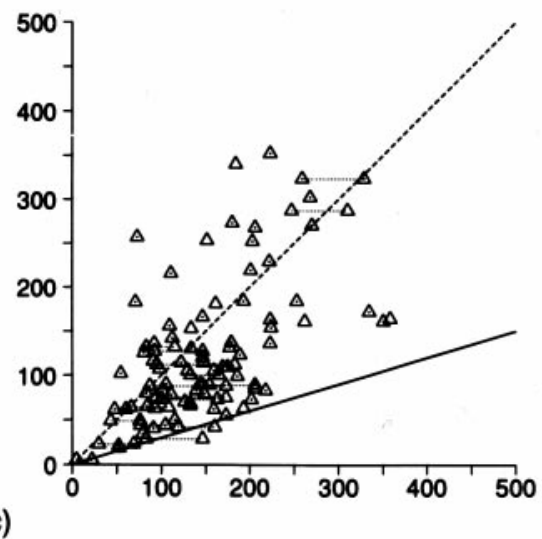

\section{C $\quad \square$ type IV DCN}

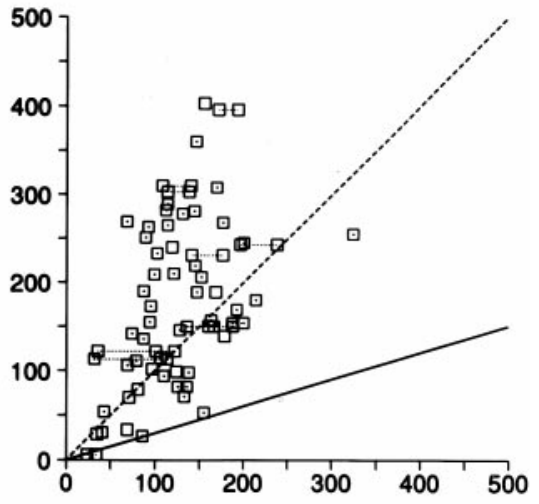

Figure 9. Relationship of maximal response (raw firing rate) to broadband noise and CF tones. Dashed line indicates equality of response; solid line indicates $\rho$ criterion of 0.3. Dotted lines join data points for short and long tone bursts if both were available for the same cell. Total number of cells $=$ 189. $A, \mathrm{O}_{\mathrm{c}}(n=11$ cells) and type II cells $(n=29)$. $B$, Type III cells (64 in DCN, 23 in DAS). Average rates (spikes per second): tones $144(n=127)$, broadband noise $126(n=104)$. $C$, Type IV cells (43 in DCN, 19 in DAS). Average rates: tones $126(n=73)$, broadband noise $177(n=62)$.

there is a tendency at the population level for less nonmonotonic behavior in response to tones. An additional property of type IV cells in the decerebrate cat (Spirou and Young, 1991; Nelken and Young, 1994) is an exquisite sensitivity to spectral features of broadband stimuli. As a further test of response similarity in the two preparations, I occasionally tested type III and IV cells for this sensitivity. A series of band-reject noise stimuli were constructed with a stopband of increasing width, always arithmetically centered on the CF. Responses to a complete series of notch widths were obtained in six cells. The type IV unit illustrated in Figure $10 A$ showed the largest effect seen. Similar to the data of Nelken and Young (1994), the cell was inhibited by a CF tone, excited by broadband noise, and progressively less driven as the stopband in the noise widened. However, in contrast to the data reported by Nelken and Young (1994), none of the notched-noise stimuli resulted in the profound inhibition seen with tone bursts. The cell in Figure $10 B$ was robustly driven by all wideband stimuli, even at high notch widths. The responses of four other cells recorded in DCN (two type III and two type IV) were intermediate between those shown in Figure 10.

\section{DISCUSSION}

The only previous reports of DAS physiology were of a preliminary nature (Kiang et al., 1973; Adams, 1976) and established that PSTH patterns were predominantly of the Pauser, Buildup, and Chopper variety. Young (1980) stimulated the DAS electrically and found that antidromically activated DCN cells gave predominantly type IV responses. On the basis of this evidence, it was proposed that these responses are associated with DCN projection neurons, whereas type II responses are derived from interneurons such as tuberculoventral cells (Wickesberg and Oertel, 1988). Consistent with that proposal, the present results show that DAS responses are predominantly type $\mathrm{III}+\mathrm{IV}$ and $\mathrm{O}_{\mathrm{c}}$, to the exclusion of type II.

Neither the response map scheme nor the PSTH classification scheme is strictly quantitative. Both rely on prototypical response features and are fuzzy at the response class borders (see Figs. 4, 5). Studies of the relationship between the two schemes (Shofner and Young, 1985; Stabler et al., 1996; Gdowski and Voigt, 1997) emphasized their incompatibility, and often the two response measures (PSTH patterns and average rate) are treated as being independent. PSTH patterns can change with frequency, SPL, and other stimulus parameters (Godfrey et al., 1975b; Shofner and Young, 1985; Rhode and Smith, 1986b; Stabler et al., 1996), and, equivalently, response maps constructed over small consecutive integration windows vary over time (Kaltenbach et al., 1989). However, these dependencies show that the two schemes are mutually constraining rather than incompatible. For example, at the risk of stating the obvious, PSTHs obtained at frequencySPL combinations in an inhibitory area of the response map must also be dominated by inhibition.

The aim of classification in the present experiments was to derive the minimal number of DCN-DAS classes that plausibly correspond to cell types differing in morphological and projectional features and was guided by the following assessment of the relevant literature. First, difficulties in classification promote the tendency to elaborate the number of (sub)types (seven response map classes in Davis et al., 1996; 17 PSTH classes in Gdowski and Voigt, 1997), although only a small number of functional elements are needed to account for DCN responses in models (Arle and Kim, 1991; Nelken and Young, 1994; Reed and Blum, 1995; Davis et al., 1996). Consequently, response classes do not carry equal weight: some classes are devices to accommodate classification difficulties (e.g., types I/III, IV-T in the response map scheme). Second, recent studies have based classification on rate-level functions for CF tones and broadband noise rather than on the complete response map (Nelken and Young, 1994; Stabler et al., 1996). Third, there is substantial evidence for structure-function associations from in vivo intracellular labeling studies in DCN and DAS (Rhode et al., 1983a,b; Smith and Rhode, 1989; Joris et al., 1992; Joris and Smith, 1995), albeit that this evidence is incomplete in different ways for different cell types (classification, anesthesia, number of cells), which clouds the relationship with the associations proposed on the basis of decerebrate studies.

On the basis of the preceding observations and the present 


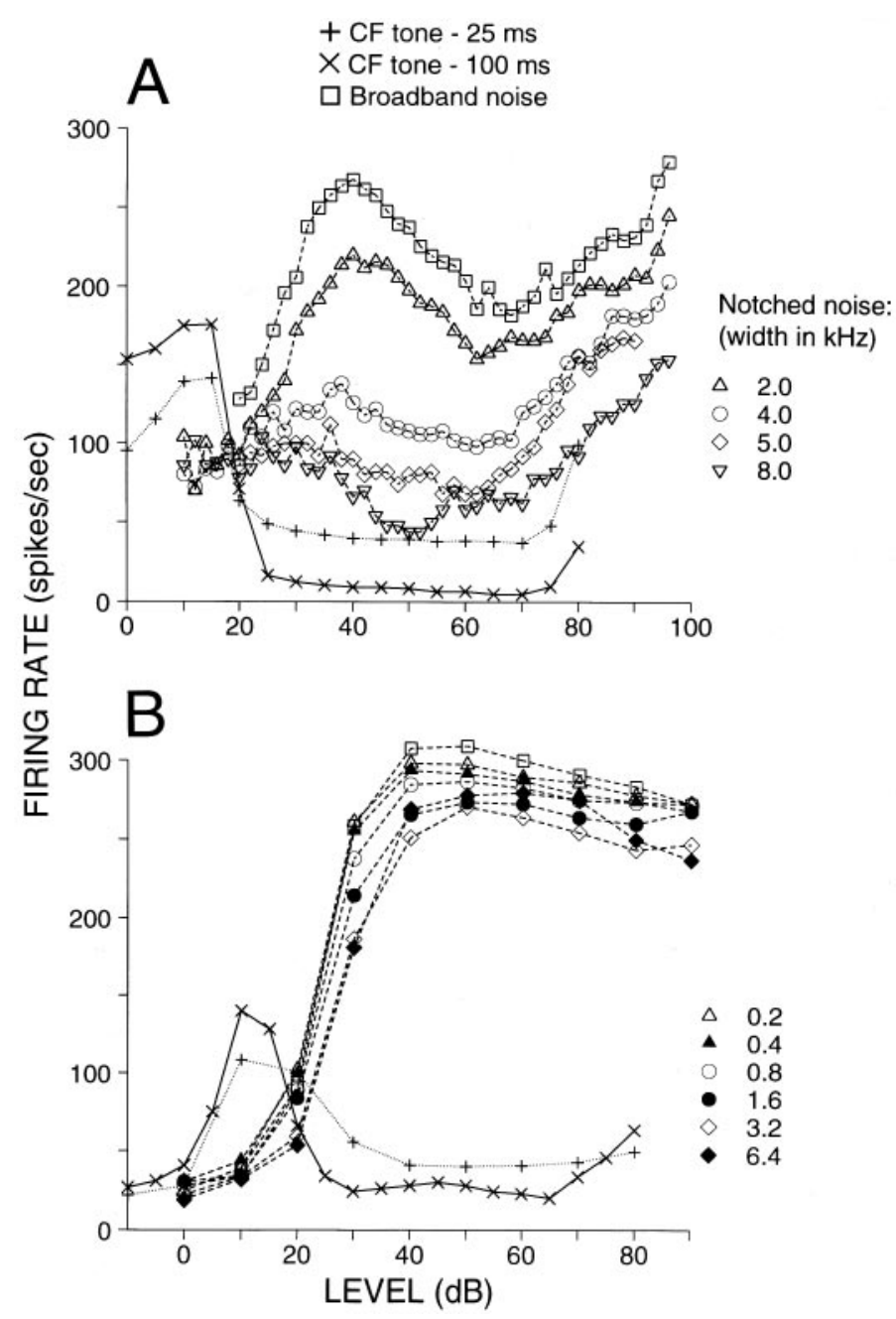

Figure 10. Responses of type IV cells, recorded in DAS of one animal, to $\mathrm{CF}$ tones and broadband and notched noise. Noise bandwidth was 40 $\mathrm{kHz}$, and notch bandwidth was varied as indicated by the symbol caption, with a nominal depth of $\geq 100 \mathrm{~dB}$ and slopes of several thousand $\mathrm{dB} /$ octave. CFs were $29 \mathrm{kHz}(A)$ and $9 \mathrm{kHz}(B)$. For $A$, an attenuator setting of $100 \mathrm{~dB}$ corresponds to a noise level of $87 \mathrm{~dB}$.

results, a plausible and parsimonious classification scheme can be derived that uses features of both schemes to a varying degree for different cell types. For a first class of responses, type II, the cardinal features are a poor response to broadband noise and a robust response to tones: the PSTH is highly variable and is not a reliable classifier (Fig. 5). These cells have low SRs and the rate-level function to tones usually has an accelerating negative slope at high SPLs. With the exception of lower maximal rates to tones (compare Fig. $9 A$ with Fig. $6 A$ in Young and Voigt, 1982), these features are consistent with those recognized by Young and coworkers (Young and Brownell, 1976; Young, 1980; Young and Voigt, 1982; Shofner and Young, 1985).

The cardinal features of a second class of responses are almost opposite: a very high response to noise and a response to tones that shows an accelerating positive slope at high SPLs (Fig. 6). This class was first recognized on the basis of the PSTH pattern (On-type $\mathrm{L}$ or $\mathrm{O}_{\mathrm{c}}$ ) and is associated with multipolar cells in the nerve root region and deep DCN (Rhode and Smith, 1986a; Smith and Rhode, 1989; Godfrey et al., 1975a,b; Joris et al., 1992; Palmer et al., 1996). The response map classification of these cells is indistinct (type III or I/III, i.e., excited by tones and broadband noise and lacking sufficient SR to test for inhibitory sidebands), but these cells do not constitute a high proportion of DCN recordings because of their anatomical location.

Regarding the final group, types III and IV, the present results suggest an interpretation that diverges from previous studies in the decerebrate cat. Definition of the type III class is too general to warrant homogeneity. It does not discriminate among several CN cell types, the distinctive PSTH patterns and morphologies of which have been well documented (e.g., multipolar cells, stellate cells, globular bushy cells, and some fusiform cells, can all be type III or I/III). On the other hand, the type III and IV cells described in this study were found in approximately equal proportions in DCN (III, 58\%; IV, 42\%; $n=110$ ) and DAS (III, $54 \%$; IV , 46\%; $n=39$ ), and with few exceptions they had PSTHs along the spectrum Pauser-Buildup/ON-I. This suggests that despite the nonspecific definition of the type III response, type III+IV responses in DCN and DAS are derived predominantly from projection neurons and not from DCN interneurons. Second, the responses are not suggestive of a type III-type IV dichotomy. Rather, these two classes appear to be the opposite poles of a continuum. To tones, there is a continuum of degrees of inhibition and PSTH shapes, but with a stereotyped dependency on SPL (Fig. 7). Not the shape of a single PSTH at a fixed suprathreshold level, but the dynamics of the PSTH changes with level, and its reflection in the rate-level function, distinguishes these cells from type II or $\mathrm{O}_{c}$ cells. To broadband noise, there is a sizeable fraction of type III + IV cells $(\sim 8-19 \%$ depending on criteria) that had a low or even inhibitory response to broadband noise. Such responses are also apparent in initial studies of the decerebrate cat as well as in more recent publications in cat and other species (Young and Brownell, 1976; Kim et al., 1990; Nelken and Young, 1994; Davis et al., 1996; Gdowski and Voigt, 1997). Thus from the present results it appears that projection cells are more varied in their responses to tones and noise than is implied by the prototypical description for the decerebrate cat, and that there is little rationale for maintaining the type III-type IV distinction rather than using a single class III+IV. This is congruent with data from other anesthetized and even unanesthetized preparations (Rhode and Smith, 1986b; Rhode and Kettner, 1987; Stabler et al., 1996).

It is not entirely clear how appropriate this characterization may be for the decerebrate animal. The type III-type IV dichotomy in that preparation is based largely on co-segregation of response properties and does not clearly map onto an interneuron-projection neuron dichotomy. Antidromic stimulation of the DAS (Young, 1980) indicates that at least some type III cells project out of the DCN, but the exact proportion is difficult to estimate because that study predates the more recent type II-type III subdivision. On the one hand, there have been no labeling studies in the decerebrate animal to refute the claim that a significant portion of DCN projection neurons have responses other than type IV. On the other hand, there is undeniably a difference in response class distribution between decerebrate and anesthetized preparations, as also observed in this study, although it is not obvious which of those preparations is the better model for the awake state. Thus, it is possible that the continuity of the type III-type IV properties as emphasized here is an anesthesia artifact. A straightforward means to resolve this issue, short of intracellular labeling studies in decerebrate animals, is to record from DAS in the decerebrate animal.

An intriguing result is the stronger response to noise in cells 
strongly inhibited by tones (Fig. 9C) compared with cells only weakly inhibited by tones (Fig. 9B). According to Nelken and Young (1994), type IV responses to tones and noise reflect different processes: the nonmonotonic response to tones is derived from inhibition by type II interneurons, whereas the response to broadband noise is limited by wideband inhibitors, presumably $\mathrm{O}_{\mathrm{c}} \mathrm{s}$. Generalizing to the III+IV class, their model predicts that cells with poor tonal responses receive weak $\mathrm{O}_{c}$ inputs but strong type II inputs, and the reverse for cells with strong tonal responses, perhaps as a consequence of the position of the fusiform cell relative to the axonal arbors of type II cells below the fusiform cell layer and the more deeply located $\mathrm{O}_{\mathrm{c}}$ cells. Interestingly, in line with this possibility is the observation by Rhode and Smith (1986b) that cells with Pauser PSTH are generally located deeper than cells with Buildup PSTH, which are more poorly driven by tones.

\section{REFERENCES}

Adams JC (1976) Single unit studies on the dorsal and intermediate acoustic striae. J Comp Neurol 170:97-106.

Adams JC, Warr WB (1976) Origins of axons in the cat's acoustic striae determined by injection of horseradish peroxidase into severed tracts. J Comp Neurol 170:107-122.

Arle JE, Kim DO (1991) Simulations of cochlear nucleus neural circuitry: excitatory-inhibitory response-area types I-IV. J Acoust Soc Am 90:3106-3121.

Chan JCK, Musicant A, Hind JE (1993) An insert earphone system for delivery of spectrally-shaped signals for physiological studies. J Acoust Soc Am 93:1496-1501.

Davis KA, Ding J, Benson TE, Voigt HF (1996) Response properties of units in the dorsal cochlear nucleus of unanesthetized decerebrate gerbil. J Neurophysiol 75:1411-1431.

Evans EF, Nelson PG (1973) The responses of single neurones in the cochlear nucleus of the cat as a function of their location and the anaesthetic state. Exp Brain Res 17:402-427.

Evans EF, Zhao W (1993) Varieties of inhibition in the processing and control of processing in the mammalian cochlear nucleus. Prog Brain Res 97:117-126.

Fernandez C, Karapas F (1967) The course and termination of the striae of Monakow and Held in the cat. J Comp Neurol 131:371-386.

Geisler CD, Sinex DG (1982) Responses of primary auditory fibers to brief tone bursts. J Acoust Soc Am 72:781-794.

Gdowski GT, Voigt HG (1997) Response map properties of units in the dorsal cochlear nucleus of barbiturate-anesthetized gerbil (Meriones unguiculatus). Hear Res 105:85-104.

Godfrey DA, Kiang NYS, Norris BE (1975a) Single unit activity in the posteroventral cochlear nucleus of the cat. J Comp Neurol 162:247-268.

Godfrey DA, Kiang NYS, Norris BE (1975b) Single unit activity in the dorsal cochlear nucleus of the cat. J Comp Neurol 162:269-284.

Joris PX, Smith PH (1995) Physiology and anatomy of type II interneurons in dorsal cochlear nucleus of the cat. Soc Neurosci Abstr 21:400.

Joris PX, Smith PH, Yin TCT (1992) Responses and projections of dorsal and intermediate stria axons, labeled with HRP or neurobiotin. Assoc Res Otolaryngol Abstr 15:58.

Kaltenbach JA, Saunders JC (1987) Spectral and temporal response patterns of single units in the chinchilla dorsal cochlear nucleus. Exp Neurol 96:406-419.

Kaltenbach JA, Gochin P, Gerstein GL (1989) Spectral time-course analysis of firing patterns in the dorsal cochlear nucleus. Hear Res 41:107-114.

Kiang NYS, Morest DK, Godfrey DA, Guinan JJ, Kane EC (1973) Stimulus coding at caudal levels of the cat's auditory nervous system: I. Response characteristics of single units. In: Basic mechanisms in hearing (Moller AR, ed), pp 455-478. New York: Academic.

Kim DO, Sirianni JG, Chang SO (1990) Responses of DCN-PVCN neurons and auditory nerve fibers in unanesthetized decerebrate cats to $\mathrm{AM}$ and pure tones: analysis with autocorrelation/power-spectrum. Hear Res 45:95-113.

Mast TE (1973) Dorsal cochlear nucleus of the chinchilla: excitation by contralateral sound. Brain Res 62:61-70.
Nelken I, Young ED (1994) Two separate inhibitory mechanisms shape the responses of dorsal cochlear nucleus type IV units to narrowband and wideband stimuli. J Neurophysiol 71:2446-2462.

Olson RE, Yee D, Rhode WS (1985) Digital system-version II. Medical Electronics Laboratory and Department of Neurophysiology. Madison, WI: University of Wisconsin.

Palmer AR, Jiang D, Marshall DH (1996) Responses of ventral cochlear nucleus onset and chopper units as a function of signal bandwidth. J Neurophysiol 75:780-794.

Reed MC, Blum JJ (1995) A computational model for signal processing by the dorsal cochlear nucleus. I. Responses to pure tones. J Acoust Soc Am 97:425-438.

Rhode WS (1976) A digital system for auditory neurophysiological research. In: Current computer technology in neurobiology (Brown PB, ed), pp 543-567. Washington, DC: Hemisphere.

Rhode WS (1990) Response properties of cochlear nucleus neurons. In: Neurobiology of hearing: The central auditory system (Altschuler RA, Hoffman D, Bobbin D, Clopton B, eds), pp 47-77. New York: Raven.

Rhode WS, Kettner RE (1987) Physiological study of neurons in the dorsal and posteroventral cochlear nucleus of the unanesthetized cat. J Neurophysiol 57:414-442.

Rhode WS, Smith PH (1986a) Encoding timing and intensity in the ventral cochlear nucleus of the cat. J Neurophysiol 56:261-286.

Rhode WS, Smith PH (1986b) Physiological studies on neurons in the dorsal cochlear nucleus of cat. J Neurophysiol 56:287-307.

Rhode WS, Oertel D, Smith PH (1983a) Physiological response properties of cells labeled intracellularly with horseradish peroxidase in cat ventral cochlear nucleus. J Comp Neurol 213:448-463.

Rhode WS, Smith PH, Oertel D (1983b) Physiological response properties of cells labeled intracellularly with horseradish peroxidase in cat dorsal cochlear nucleus. J Comp Neurol 213:426-447.

Schreiner CE, Sutter ML (1992) Topography of excitatory bandwidth in cat primary auditory cortex: single-neuron versus multiple-neuron recordings. J Neurophysiol 68:1487-1502.

Shofner WP, Young ED (1985) Excitatory/inhibitory response types in the cochlear nucleus: relationships to discharge patterns and responses to electrical stimulation of the auditory nerve. J Neurophysiol 54:917-939.

Smith PH, Rhode WS (1989) Structural and functional properties distinguishing two types of multipolar cells in the cat ventral cochlear nucleus. J Comp Neurol 282:595-616.

Sokolich WG (1977) Improved acoustic system for auditory research (Abstr). J Acoust Soc Am 62:S12.

Spirou GA, Young ED (1991) Organization of dorsal cochlear nucleus type IV unit response maps and their relationship to activation by bandlimited noise. J Neurophysiol 66:1750-1768.

Stabler SE, Palmer AR, Winter IM (1996) Temporal and mean rate discharge patterns of single units in the dorsal cochlear nucleus of the anesthetized guinea pig. J Neurophysiol 76:1667-1688.

Voigt HF, Young ED (1980) Evidence of inhibitory interactions between neurons in dorsal cochlear nucleus. J Neurophysiol 44:76-96.

Voigt HF, Young ED (1988) Neural correlations in the dorsal cochlear nucleus: pairs of units with similar response properties. J Neurophysiol 59:1014-1032.

Voigt HF, Young ED (1990) Cross-correlation analysis of inhibitory interactions in dorsal cochlear nucleus. J Neurophysiol 64:1590-1610.

Warr WB (1969) Fiber degeneration following lesions in the posteroventral cochlear nucleus of the cat. Exp Neurol 23:140-155.

Wickesberg RE, Oertel D (1988) Tonotopic projection from the dorsal to the anteroventral cochlear nucleus of mice. J Comp Neurol 268:389-399.

Winter IM, Palmer AR (1995) Level dependence of cochlear nucleus onset unit responses and facilitation by second tones or broadband noise. J Neurophysiol 73:141-159.

Young ED (1980) Identification of response properties of ascending axons from dorsal cochlear nucleus. Brain Res 200:23-37.

Young ED (1984) Response characteristics of neurons of the cochlear nuclei. In: Hearing science (Berlin CI, ed), pp 424-460. San Diego: College-Hill.

Young ED, Brownell WE (1976) Responses to tones and noise of single cells in dorsal cochlear nucleus of unanesthetized cats. J Neurophysiol 39:282-300.

Young ED, Voigt HF (1982) Response properties of type II and type III units in dorsal cochlear nucleus. Hear Res 6:153-169. 